\title{
Glucocorticoid receptor dimerization induces MKP1 to protect against TNF-induced inflammation
}

\author{
Sofie Vandevyver, ${ }^{1,2}$ Lien Dejager, ${ }^{1,2}$ Tom Van Bogaert, ${ }^{1,2}$ Anna Kleyman, ${ }^{3}$ Yusen Liu, ${ }^{4}$ \\ Jan Tuckermann, ${ }^{5}$ and Claude Libert ${ }^{1,2}$
}

\begin{abstract}
1Department for Molecular Biomedical Research, VIB, Ghent, Belgium. ²Department of Biomedical Molecular Biology, Ghent University, Ghent, Belgium. ${ }^{3}$ Leibniz Institute for Age Research — Fritz Lipmann Institute e.V., Jena, Germany. ${ }^{4}$ Department of Pediatrics, Ohio State University, College of Medicine, Columbus, Ohio, USA. Institute for General Zoology and Endocrinology, University of Ulm, Ulm, Germany.
\end{abstract}

\begin{abstract}
Glucocorticoids acting through the glucocorticoid receptor (GR) inhibit TNF-induced lethal inflammation. Here, we demonstrate that GR dimerization plays a role in reducing TNF sensitivity. In mutant mice unable to dimerize GR, we found that TNF failed to induce MAPK phosphatase 1 (MKP1). We assessed TNF sensitivity in $\mathrm{Mkp1}^{-/-}$mice and found increased inflammatory gene induction in livers, increased circulating cytokines, cell death in intestinal epithelium, severe intestinal inflammation, hypothermia, and death. $M k p 1^{-/-}$mice had increased levels of phosphorylated JNK, which promotes apoptosis, in liver tissue. We further examined JNK-deficient mice for their response to TNF. Although $\mathrm{Jnk1}^{-/-}$mice showed no change in sensitivity to TNF, $J n k 2^{-/-}$mice were significantly protected against TNF, identifying JNK2 as an essential player in inflammation induced by TNF. Furthermore, we found that loss of $J n k 2$ partially rescued the increased sensitivity of $\mathrm{Mkp1}^{-/-}$and mutant GR mice to TNF. Our data show that GR dimerization inhibits JNK2 through MKP1 and protects from TNF-induced apoptosis and lethal inflammation.
\end{abstract}

\section{Introduction}

TNF plays an important role in inflammatory disorders such as rheumatoid arthritis, inflammatory bowel disease (IBD), and psoriasis $(1,2)$. Biological drugs that inhibit TNF are effective, despite some limited side effects (3). However, the mechanism by which TNF activates and sustains the inflammatory response is not yet clear. TNF induces transcription factors, such as NF-KB and AP-1, that stimulate the expression of hundreds of genes, activate cell death, and cause tissue damage (4). Clinical and animal studies have identified hypotension, liver toxicity, and bowel necrosis as the major determinants of TNF lethality (5).

Both exogenous and endogenous glucocorticoids (GCs) protect against TNF-induced lethal inflammation $(6,7)$. The binding of GCs to the GC receptor (GR) protects against TNF lethality, as shown by the use of GR blockers and GR-deficient mice $(8,9)$. However, the protective mechanism is not fully elucidated. GCactivated GR can form dimers, which bind to GC response elements (GREs) (1) and lead to transactivation (TA) of metabolic and antiinflammatory genes. GR can also transrepress genes by binding as a monomer to transcription factors such as NF- $\mathrm{KB}$ and AP-1 $(10,11)$. It has been proposed that the antiinflammatory effects of GR are mainly mediated by transrepression (TR) and that the induction of unwanted side effects of GC therapy (such as type 2 diabetes) is mediated by TA. Therefore, researchers have been developing ligands that favor GR monomers $(12,13)$. However, several transactivated genes that have been identified encode strong antiinflammatory molecules, such as MKP1 $(14,15)$. MKP1 (encoded by Mkp1; also known as dual-specificity phosphatase-1, Dusp1) is a member of the family of dual-specificity phosphatases, which preferentially dephosphorylate MAPKs, such as p38 and JNK (16).

Conflict of interest: The authors have declared that no conflict of interest exists. Citation for this article: J Clin Invest. 2012;122(6):2130-2140. doi:10.1172/JCI60006.
Since these MAPKs are essential in the initiation of inflammation, MKP1 has been described as critical for the resolution of inflammation. Indeed, $\mathrm{Mkp1}^{-/-}$mice are very sensitive in models of endotoxemia, sepsis, and other inflammatory diseases (17-19).

To identify the protective mechanism of endogenous GCs and GR, we here used mice expressing a mutant version of the GR protein, namely $\mathrm{GR} \mathrm{dim} / \mathrm{dim}$. This mutant protein carries a single point mutation (A458T) that prevents it from forming dimers $(20,21)$. Hence, GR ${ }^{\mathrm{dim} / \mathrm{dim}}$ mice are largely devoid of TA induced by GR dimers and are more sensitive to inflammatory diseases, such as contact hypersensitivity and sepsis $(22,23)$. These findings indicate that at least $1 \mathrm{GRE}$ gene is induced by GR and has antiinflammatory functions in the GR $\mathrm{dim}^{\mathrm{dim}}$ model, and perhaps in other models and diseases as well.

In this work, we used GR ${ }^{\mathrm{dim} / \mathrm{dim}}$ mice to study the contribution of GRE genes to the protection against the lethal effects of TNF. We concluded that endogenous GCs protected against TNF lethality in a GR dimer-dependent manner. This protection specifically involved MKP1-mediated dephosphorylation of the proapoptotic JNK2 MAPK $(24,25)$.

\section{Results}

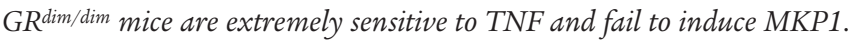
Whether the TA potential of GR is necessary for its antiinflammatory activity is somewhat controversial. In this study, we investigated whether the induction of GRE genes is necessary for the antiinflammatory functions counteracting TNF lethality. We injected WT control (GR $\left.\mathrm{GR}^{\mathrm{wt}} / \mathrm{wt}\right)$ and $\mathrm{GR}^{\mathrm{dim} / \mathrm{dim}}$ mice i.p. with $25 \mu \mathrm{g} \mathrm{TNF}$ (a nonlethal dose for FVB/N mice) and monitored survival and body temperature. Mortality rate was significantly higher and hypothermia more pronounced in $\mathrm{GR}^{\mathrm{dim} / \mathrm{dim}}$ than in $\mathrm{GR}^{\mathrm{wt} / \mathrm{wt}}$ mice (Figure 1, A and B). Because IL-6 level is a good indicator of TNF sensitivity $(26,27)$, we measured IL-6 protein levels in circulation 
A

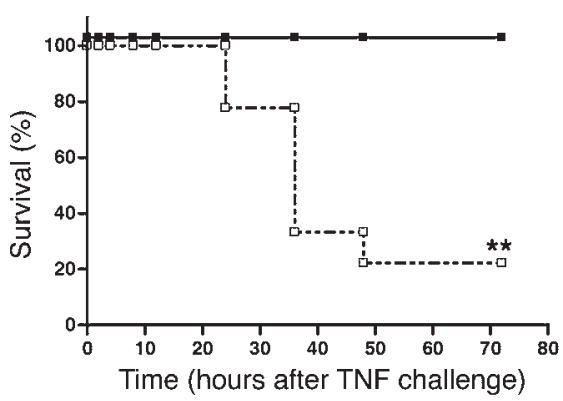

D

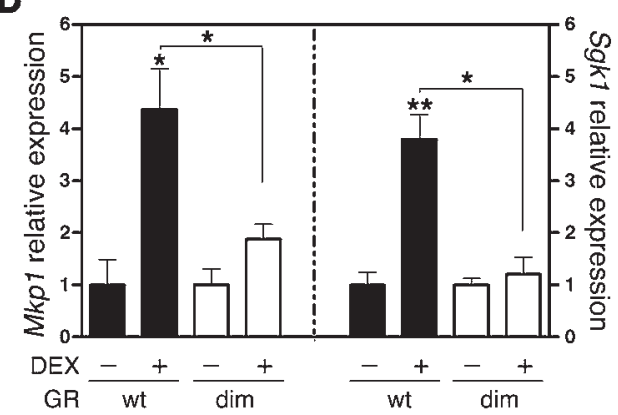

B

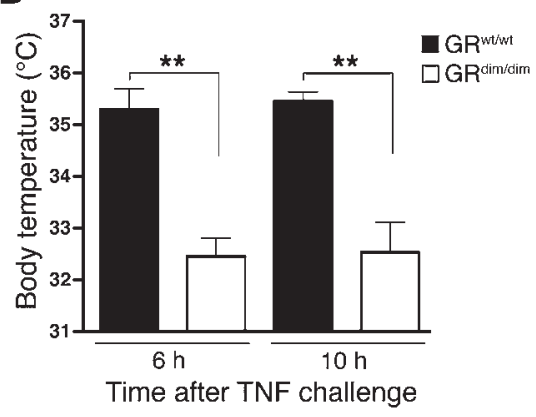

E

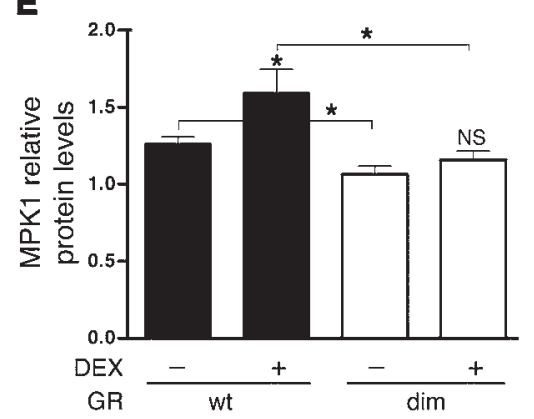

C

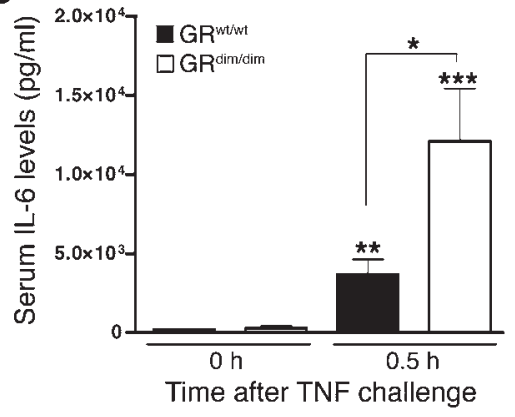

F

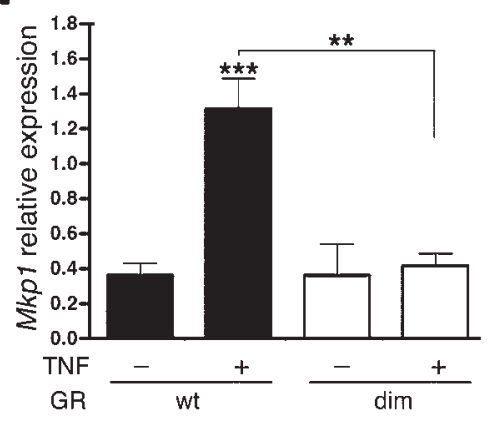

Figure 1

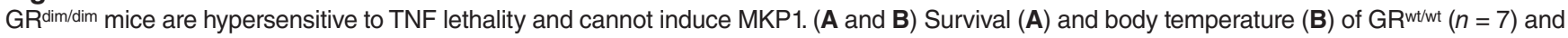
$\mathrm{GR}^{\text {dim/dim }}(n=9)$ mice after i.p. injection of $25 \mu \mathrm{g} \mathrm{TNF} .{ }^{* *} P<0.01$, GR ${ }^{\text {dim/dim }}$ vs. GR ${ }^{\text {wtwt }}$. (C) IL-6 concentration in serum 0 and 0.5 hours after injection of $25 \mu \mathrm{g} \mathrm{TNF}\left(n=5\right.$ per group). ${ }^{\star \star} P<0.01,{ }^{* \star} P<0.001$ vs. 0 hours; ${ }^{\star} P<0.05$ as indicated by brackets. (D) Mice were injected i.p. with PBS or $500 \mu \mathrm{g}$ DEX. 1 hour later, they were euthanized, and livers were harvested for qPCR analysis of Mkp1 and Sgk1 levels ( $n=4$ per group). (E) Mice were injected i.p. with PBS or $500 \mu \mathrm{g}$ DEX. 1 hour later, mice were euthanized, and livers were harvested for ELISA of MKP1 protein levels $(n=6$ per group). (F) qPCR analysis of $M k p 1$ mRNA expression in livers of mice treated with $25 \mu \mathrm{g}$ TNF for 0.5 hours $(n=5$ per group). (D-F) * $P<0.05$, ${ }^{\star \star} P<0.01,{ }^{\star \star \star} P<0.001$ vs. PBS or as indicated by brackets. (A-F) Black bars and symbols, GR ${ }^{\text {wtwtw }}$ white bars and symbols, GR ${ }^{\text {dim/dim. }}$

0.5 hours after TNF stimulation. The significantly higher IL-6 levels in $\mathrm{GR}^{\mathrm{dim} / \mathrm{dim}}$ mice (Figure 1C) confirmed their hypersensitivity to TNF. Furthermore, H\&E staining of ileum samples showed that TNF treatment resulted in more severe intestinal damage in GR $\mathrm{dim} / \mathrm{dim}$ than in $\mathrm{GR}^{\mathrm{wt} / \mathrm{wt}}$ mice (Supplemental Figure 1A; supplemental material available online with this article; doi:10.1172/JCI60006DS1). These data showed that dimerization of GR was essential for protection against TNF-induced shock, presumably by the induction of antiinflammatory GRE genes by endogenous GCs.

One of the most potent antiinflammatory genes induced by GR is $M k p 1$. To evaluate $M k p 1$ expression in our setting, $\mathrm{GR}^{\mathrm{wt} / \mathrm{wt}}$ and $\mathrm{GR}^{\mathrm{dim} / \mathrm{dim}}$ mice were injected i.p. with $500 \mu \mathrm{g}$ of a synthetic GC, dexamethasone (DEX), or with PBS. Liver samples were isolated 1 hour after DEX treatment, and mRNA expression of Mkp1 and Sgk1, a well-known GR dimer-dependent TA gene, was measured by quantitative real-time PCR (qPCR). DEX treatment of GR ${ }^{\mathrm{wt} / \mathrm{wt}}$ mice resulted in a strong induction of $M k p 1$ and $S g k 1$ expression in liver; this induction was significantly weaker in GR ${ }^{\mathrm{dim} / \mathrm{dim}}$ mice (Figure 1D). Because Mkp1 regulation by GCs is not restricted to the transcriptional level, MKP1 protein levels were also measured. MKP1 protein was induced after DEX injection only in GR ${ }^{\mathrm{wt} / \mathrm{wt}}$ mice (Figure 1E), which indicates that the induction of both $M k p 1$ gene expression and MKP1 protein relies on GR dimerization. Since the regulation of MKP1 is controversial, we performed ChIP analysis to test whether the GR in GR $\mathrm{dim} / \mathrm{dim}$ mice is indeed unable to bind to the GRE of the $M k p 1$ gene. GR ${ }^{\mathrm{wt}} / \mathrm{wt}$ and $\mathrm{GR}^{\mathrm{dim} / \mathrm{dim}}$ mice were injected i.p. with $500 \mu \mathrm{g}$ DEX, and liver samples were isolated at time point 0 or after 1 hour of DEX treatment. ChIP analysis was performed on these liver samples, and the isolated DNA was checked for $M k p 1$ expression. The results showed that DEX treatment of $\mathrm{GR}^{\mathrm{wt} / \mathrm{wt}}$ mice resulted in strong binding of GR to Mkp1 (Supplemental Figure $1, \mathrm{~B}-\mathrm{E})$. This binding was substantially reduced in $\mathrm{GR}^{\mathrm{dim} / \mathrm{dim}}$ mice, which indicates that the binding of GR to Mkp1 and subsequent induction of this gene indeed require GR dimerization.

Furthermore, as it is known that inflammatory stimuli can also induce Mkp1, most likely via the production of endogenous GCs, we investigated the induction of $M k p 1$ after TNF treatment. We injected GR ${ }^{\mathrm{wt} / \mathrm{wt}}$ and $\mathrm{GR}^{\mathrm{dim} / \mathrm{dim}}$ mice i.p. with $25 \mu \mathrm{g}$ TNF and harvested liver samples after 0.5 hours. In GR ${ }^{\mathrm{wt} / \mathrm{wt}}$ mice, TNF treatment resulted in the induction of $M k p 1$, whereas in $\mathrm{GR}^{\mathrm{dim} / \mathrm{dim}}$ mice, this induction was significantly reduced (Figure $1 \mathrm{~F}$ ). These data indicate that GR dimerization is necessary for the induction of $M k p 1$ by DEX or by endogenous GCs induced by TNF. Taken together, our data demonstrated that dimerization of GR was indispensable for protection against TNF lethality. Furthermore, our findings provided evidence that Mkp1 is a GR dimer-dependent gene that might be involved in this protection against TNF.

$M k p 1^{-1-}$ mice are bypersensitive to TNF lethality. To examine whether MKP1 is indeed a critical player in the protection against TNFinduced shock, we injected $M k p 1^{+/+}$and $M k p 1^{-/-}$mice i.p. with $5 \mu \mathrm{g}$ TNF, which is not lethal for normal C57BL6/J mice. Mortality rate was higher and hypothermia was more pronounced in $M k p 1^{-/-}$than 
A
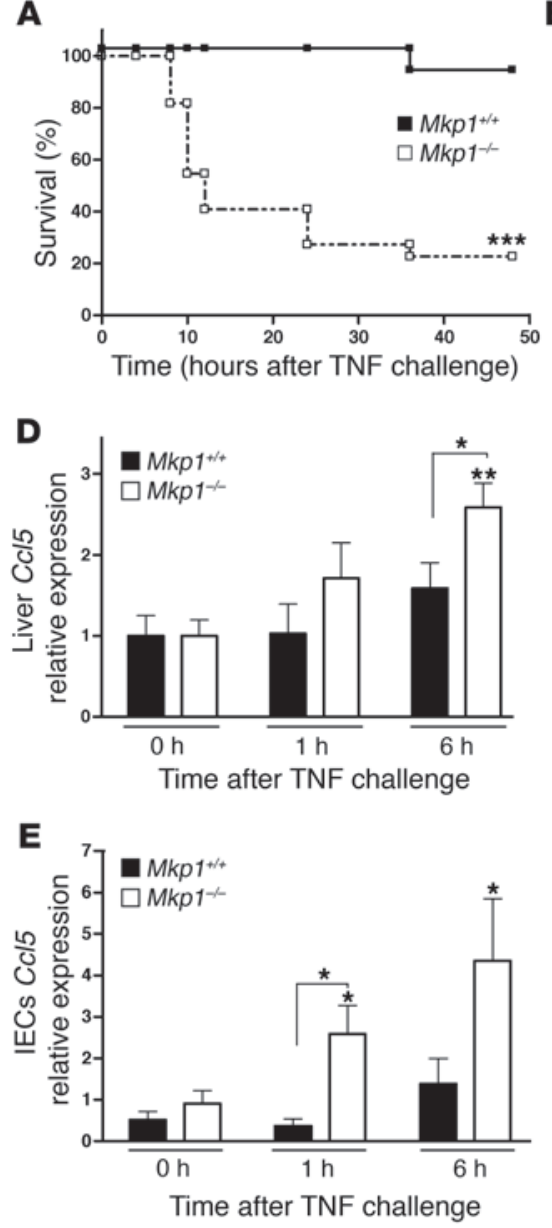

$\mathbf{F}$
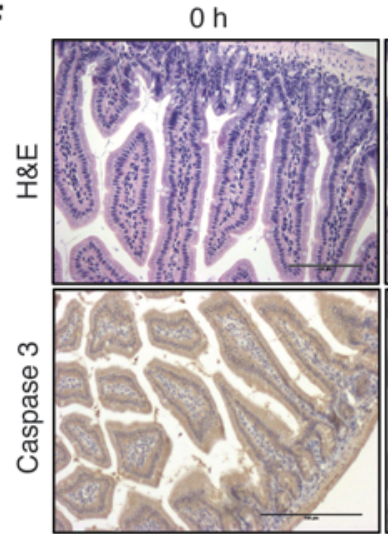

G

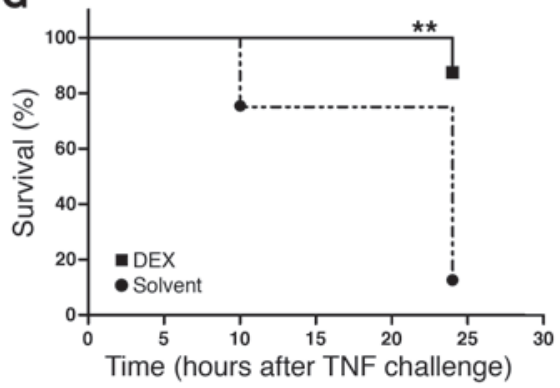

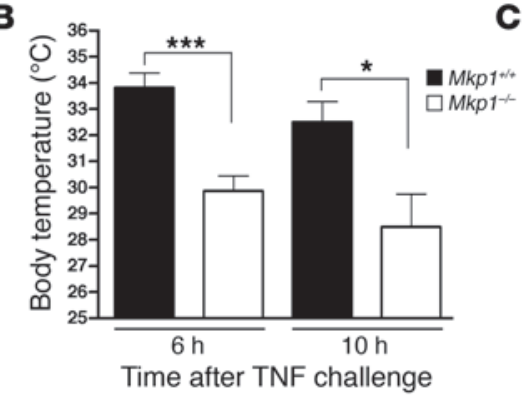
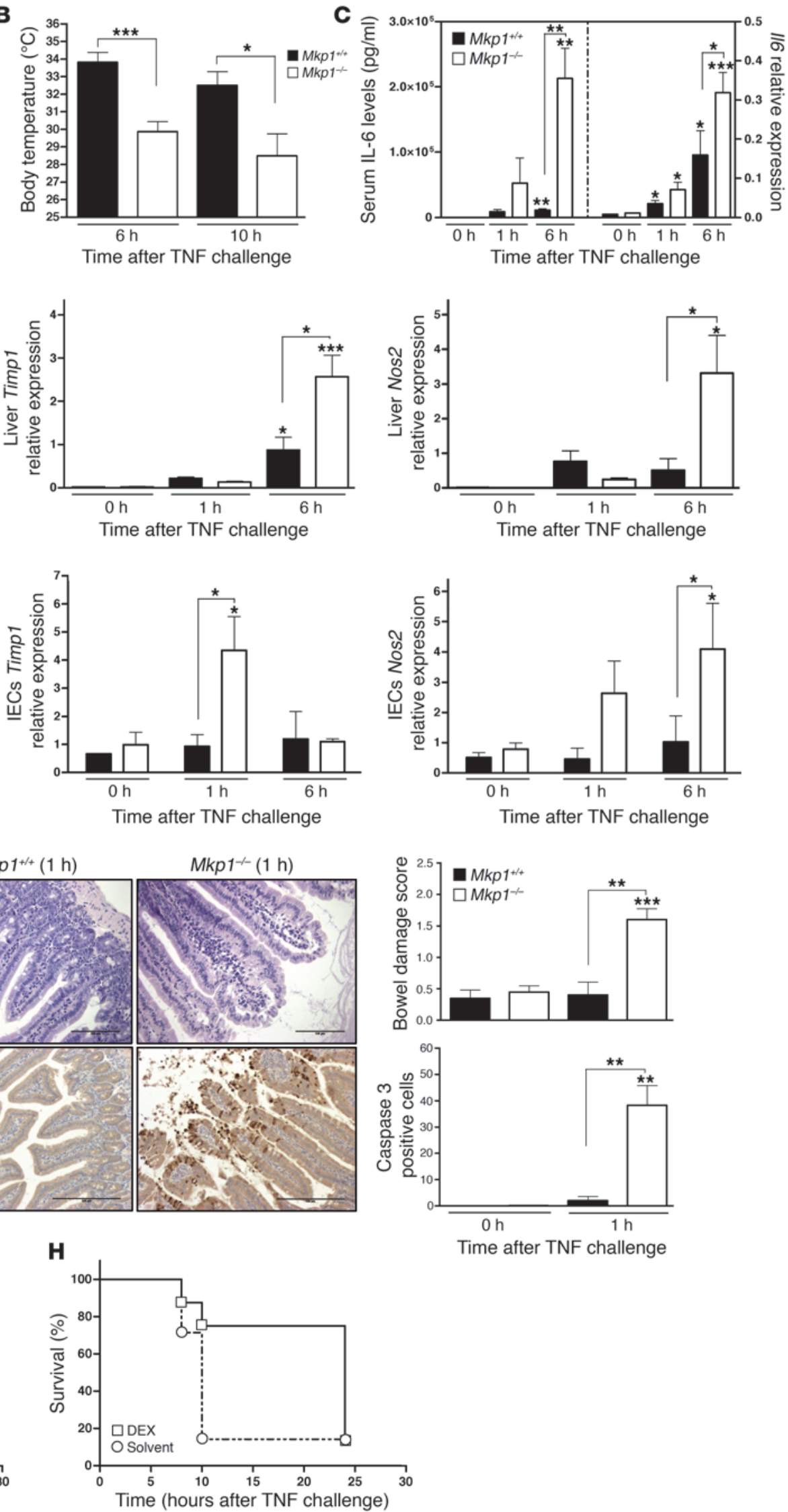


\section{Figure 2}

$M k p 1^{-/-}$mice are hypersensitive to TNF-induced lethality. (A and B) Survival (A) and body temperature (B) of $\mathrm{Mkp1}^{+/+}(n=12)$ and $\mathrm{Mkp1}^{-/-}(n=22)$ mice after injection of $5 \mu \mathrm{g}$ TNF. ${ }^{*} P<0.05$, ${ }^{* * *} P<0.001, \mathrm{Mkp1}^{-/-}$vs. $\mathrm{Mkp1}^{+/+}$. (C) Serum IL-6 levels and liver II6 mRNA levels 0,1 , and 6 hours after $5 \mu \mathrm{gTNF}$ ( $n=5$ per group). ( $\mathbf{D}$ and E) Mice were injected i.p. with $5 \mu \mathrm{g} T \mathrm{NF}$, and 0,1 , and 6 hours later, they were euthanized, and livers (D) and IECs (E) were isolated for qPCR analysis of Cc/5, Timp1 and Nos2 levels ( $n=5$ per group). (F) Standard H\&E and active caspase 3 staining of ileum samples $(n=5$ per group). Representative images are shown. The ileum was sampled 0 and 1 hour after injection of $5 \mu \mathrm{g}$ TNF. The micrograph at the 0 -hour time point is representative of both $\mathrm{Mkp1}^{+/+}$and $\mathrm{Mkp1}^{-/-}$mice. Scale bars: $100 \mu \mathrm{m}$. Original magnification, $\times 40$. $(\mathbf{C}-\mathbf{F}){ }^{*} P<0.05$, ${ }^{\star \star} P<0.01$, ${ }^{* * *} P<0.001$ vs. 0 hours or as indicated by brackets. ( $\mathbf{G}$ and $\mathbf{H}$ ) Survival of $\mathrm{Mkp1}^{+/+}(\mathbf{G})$ and $M \mathrm{kp} 1^{-/-}(\mathbf{H})$ mice pretreated with $10 \mathrm{mg} / \mathrm{kg}$ DEX (squares; $n=8$ per group) or solvent (circles; $n=8\left[M k p 1^{+/+}\right]$; $\left.7\left[\mathrm{Mkp1}^{\left.-{ }^{-}\right]}\right]\right)$and injected with $15 \mu \mathrm{g}(\mathbf{G})$ or $7.5 \mu \mathrm{g}(\mathbf{H})$ TNF. ${ }^{* *} P<0.01$, DEX vs. solvent. $(\mathbf{A}-\mathbf{H})$ Black bars and symbols, Mkp1+/+; white bars and symbols, $\mathrm{Mkp1}^{-1-}$.

in $\mathrm{Mkp}^{+/+}$mice (Figure 2, A and B). These findings indicate that MKP1 plays a crucial role in controlling TNF lethality. To investigate the underlying mechanism, $\mathrm{Mkp}^{1^{+/+}}$and $\mathrm{Mkp1}^{-/-}$mice were injected i.p. with $5 \mu \mathrm{g}$ TNF, and blood, liver, and ileum samples were obtained 0,1 , and 6 hours after TNF treatment. We measured IL-6 protein in circulation and $I l 6$ gene expression levels in liver. TNF induced high levels of hepatic Il6 mRNA and serum IL-6 protein 6 hours after TNF treatment, especially in $M k p 1^{-/-}$mice
(Figure 2C). Several other cytokines and chemokines in circulation were also higher in $M k p 1^{-/-}$than in $M k p 1^{+/+}$mice, especially 6 hours after TNF treatment (Supplemental Figure 2). Additionally, we tested the expression levels of different TNF-induced proinflammatory genes in liver samples and in intestinal epithelial cells (IECs). Again, $M k p 1^{-/-}$livers had significantly higher mRNA levels of Ccl5 (encoding CCL5 or RANTES), Timp1 (encoding the MMP inhibitor TIMP1) and Nos2 (encoding iNOS) 6 hours after TNF treatment (Figure 2, D and E). Strikingly, $M k p 1^{-/-}$mice had significantly higher mRNA levels of these proinflammatory genes in IECs as early as 1 hour after TNF. These results indicated that MKP1 has an antiinflammatory effect that protects against TNFinduced lethal inflammation.

As it was recently shown that MKP1 inhibits TNF-induced endothelial barrier dysfunction and apoptosis in HUVECs (28), and since TNF can cause intestinal damage and enterocyte apoptosis $(5,29)$, we investigated acute cell death in ileum samples of $\mathrm{Mkp1}^{+/+}$ and $\mathrm{Mkp}^{-/-}$mice using H\&E staining. As early as 1 hour after TNF challenge, the toxic effect of TNF was much more pronounced in $M k p 1^{-/-}$than in $\mathrm{Mkp1}^{+/+}$mice (Figure 2F). The intestinal damage was mainly characterized by loosening of the lamina propria, erosion of the villi, and loss of goblet cells. The degree of intestinal damage was scored according to a previously published method (30). Intestines of $\mathrm{Mkp1}^{-/-}$mice were significantly more damaged than those of control $\mathrm{Mkp1}^{+/+}$mice (Figure 2F). Furthermore, ileum samples were stained for active caspase 3 as a marker of apoptosis. In agreement with the H\&E staining, we found significantly more cells expressing active caspase 3 in ileum samples of $\mathrm{Mkp}^{1^{-/-}}$mice

\section{Figure 3}

JNK phosphorylation in liver is higher in $\mathrm{Mkp1}^{-/-}$and $\mathrm{GR}^{\mathrm{dim} / \mathrm{dim}}$ mice. (A) Western blot analysis of phospho-JNK1/2 protein levels in livers of $\mathrm{Mkp1}^{+/+}$and $\mathrm{Mkp1}^{-/-}$ mice. Mice were injected i.p. with $5 \mu \mathrm{gTNF}$, and livers were harvested at the indicated times after challenge. The phospho-JNK1/2 bands (46 kDa and $54 \mathrm{kDa}$ ) were normalized to the intensities of the total JNK1/2 and actin bands (42 kDa). Black bars, $M k p 1^{+/+}$; white bars, $\mathrm{Mkp1}^{-/-}$. (B) Western blot analysis of phospho-JNK1/2 protein levels in livers of $G^{\text {wt }} / \mathrm{wt}$ and $G R^{\text {dim/dim }}$ mice. Mice were treated with $25 \mu \mathrm{g}$ TNF; 0 and 0.5 hours later, they were euthanized, and livers were obtained for Western blot analysis. Normalized values are also shown. Black bars, GRwt/wt; white bars, GR ${ }^{\mathrm{dim} / \mathrm{dim}}$. (A and B) ${ }^{*} P<0.05,{ }^{*} P<0.01$, ${ }^{* * *} P<0.001$ vs. 0 hours or as indicated by brackets. See complete unedited blots in the supplemental material.
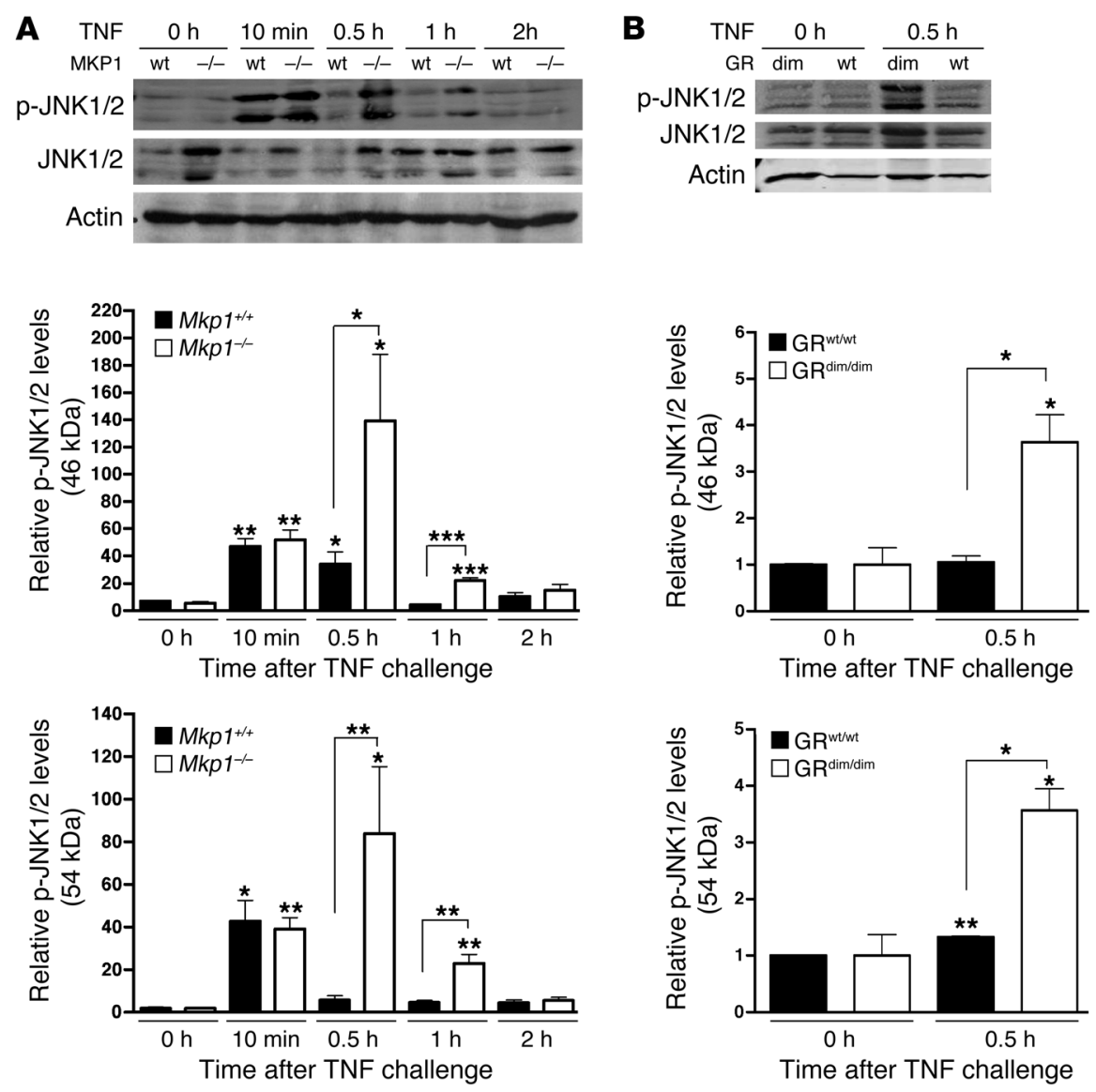
A

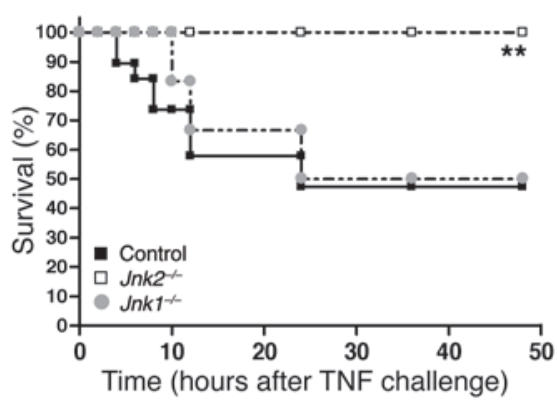

D

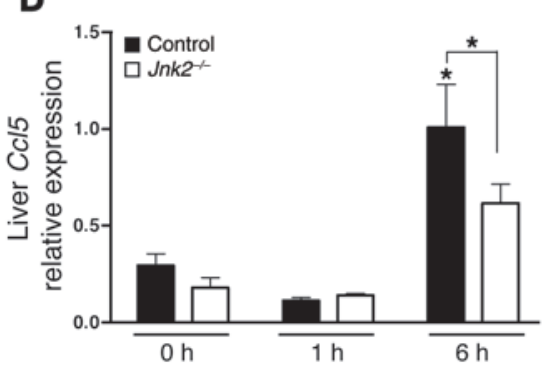

Time after TNF challenge

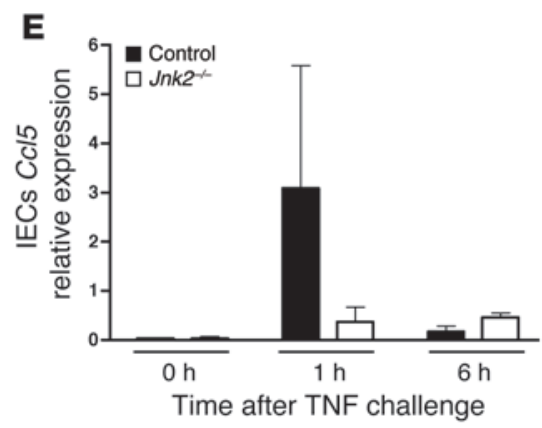

B
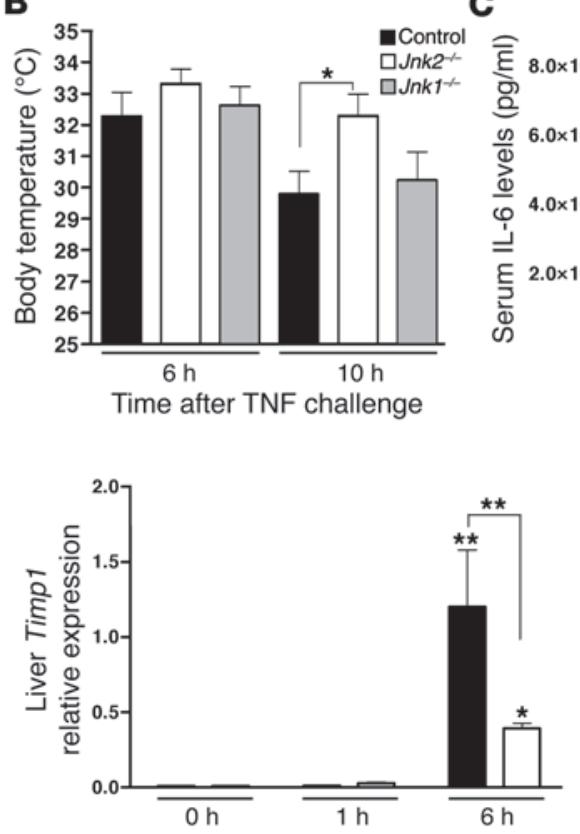

Time after TNF challenge

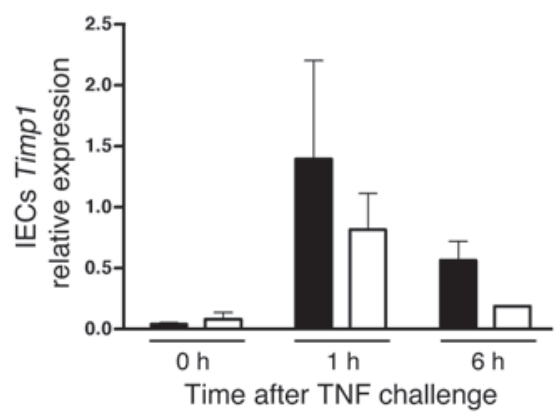

F

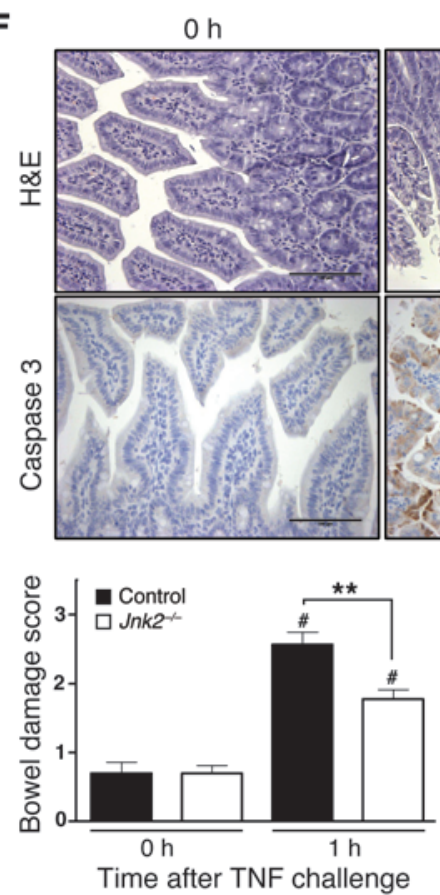

$J n k 2^{+/+}(1 \mathrm{~h})$
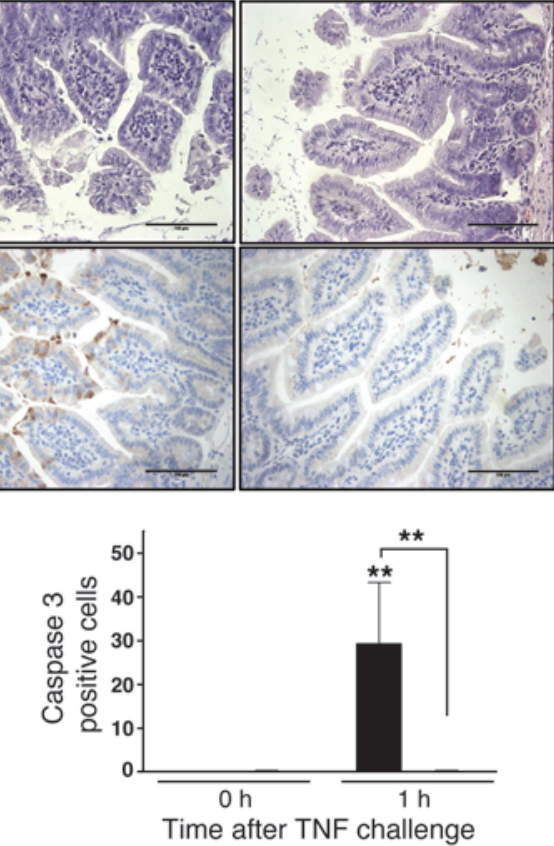
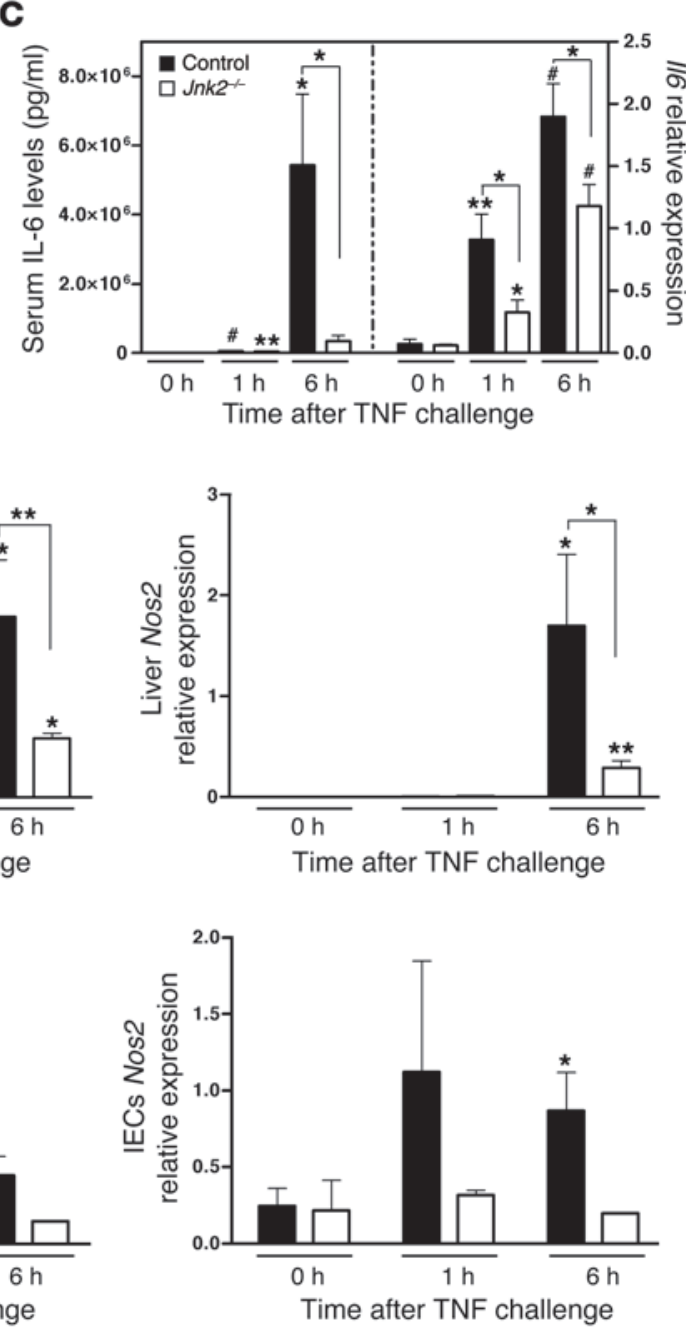

Time after TNF challenge

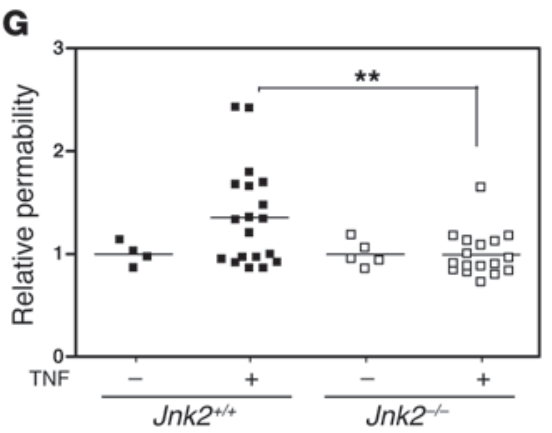




\section{Figure 4}

Jnk2-l- mice are resistant to TNF-induced shock. (A) Survival of control

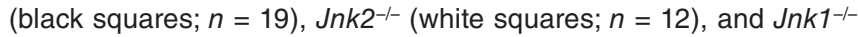
(gray circles; $n=6$ ) mice after i.p. injection of $10 \mu \mathrm{g}$ TNF. ${ }^{\star \star} P<0.01$ vs. control. (B) Body temperature of control $(n=12)$, Jnk2-/- $(n=12)$, and Jnk $1^{-1-}(n=6)$ mice after injection of $10 \mu \mathrm{g}$ TNF. ${ }^{*} P<0.05$. (C) Serum IL-6 levels and liver $/ 16$ mRNA levels 0,1 , and 6 hours after challenge with $10 \mu \mathrm{g}$ TNF ( $n=5$ per group). ( $\mathbf{D}$ and $\mathbf{E}$ ) Mice were injected i.p. with $10 \mu \mathrm{g}$ TNF; 0,1 , and 6 hours later, they were euthanized, and livers (D) and IECs (E) were obtained for qPCR analysis of Cc/5, Timp1, and Nos2 levels ( $n=5$ per group). (F) Standard H\&E and active caspase 3 staining of ileum samples ( $n=5$ per group). Representative images are shown. The ileum was sampled 0 and 1 hours after TNF injection. The micrograph at 0 hours is representative of both control and Jnk2-/- mice. Scale bars: $100 \mu \mathrm{m}$. Original magnification, $\times 40$. (C-F) ${ }^{\star} P<0.05$, ${ }^{\star *} P<0.01,{ }^{\#} P<0.001$ vs. 0 hours or as indicated by brackets. (G) Relative permeability 8 hours after injection of $10 \mu \mathrm{g}$ TNF or PBS. ${ }^{* \star} P<0.01$. (B-G) Black bars and symbols, control; white bars and symbols, Jnk2--; gray bars and symbols, Jnk1 $1^{---}$.

(Figure 2F). These data indicate that within 1 hour after TNF treatment, $M k p 1^{-1-}$ mouse intestine is severely damaged because of a high rate of apoptosis combined with severe inflammation.

Additionally, to investigate whether GC inhibition of the response to TNF occurs through MKP1, we examined whether pretreating $M k p 1^{-1-}$ mice with endogenous GCs can protect against TNFinduced lethal shock. We injected the mice with $10 \mathrm{mg} / \mathrm{kg} \mathrm{DEX}$ and 0.5 hours later with $\mathrm{LD}_{80}$ of TNF (15 $\mu \mathrm{g}$ for $\mathrm{Mkp}^{+/+} ; 7.5 \mu \mathrm{g}$ for $\left.M k p 1^{-/-}\right)$. In keeping with previous reports by our group $(7,9)$, $\mathrm{Mkp}^{+/++}$mice were protected against TNF by pretreatment with DEX compared with mice pretreated with diluted methanol solvent $(90 \%$ vs. $10 \%$ survival; Figure $2 \mathrm{G}$ ). However, pretreatment of $M k p 1^{-/-}$mice with DEX or solvent failed to protect them against TNF lethality (10\% survival; Figure $2 \mathrm{H}$ ). These data demonstrated that MKP1 was indispensable in the protective action of GCs against TNF.

Prolonged JNK activation in Mkp1-/- and GR dim/dim mice. MKP1 is known to dephosphorylate and hence inactivate MAPKs, particularly JNK and p38, but also ERK (16). As MAPKs are activated by TNF and mediate part of the TNF proinflammatory induction profile (31), we examined the status of activated MAPKs in liver samples of $M k p 1^{+/+}$and $M k p 1^{-/-}$mice. Both mouse groups were injected i.p. with $5 \mu \mathrm{g}$ TNF and sacrificed at time point 0 or after 10 minutes or $0.5,1$, or 2 hours, and hepatic MAPK levels were examined. We observed rapid induction of phospho-JNK1/2 10 minutes after TNF injection in both $\mathrm{Mkp1}^{+/+}$and $M k p 1^{-{ }^{--}}$mice (Figure 3A). This induction declined rapidly in $M k p 1^{+/+}$mice, starting 0.5 hours after TNF injection, when phospho-JNK1/2 levels in $\mathrm{Mkp1}^{-/-}$mice were still increasing (Figure 3A and Supplemental Figure 3). These data indicate that TNF treatment results in prolonged activation of JNK1/2 in $\mathrm{Mkp1}^{-/-}$compared with $M k p 1^{+/+}$mice. Levels of phospho-ERK and phospho-p38 were also examined, but no differences between $M k p 1^{+/+}$and $M k p 1^{-/-}$mice were observed (Supplemental Figure 4, A and B).

Because $\mathrm{GR}^{\mathrm{dim} / \mathrm{dim}}$ mice were very sensitive to TNF and had weaker induction of MKP1, it is conceivable that these mice also display stronger activation of JNK1/2 upon TNF challenge. Therefore, we evaluated phospho-JNK1/2 levels 0.5 hours after TNF challenge in $\mathrm{GR}^{\mathrm{wt} / \mathrm{wt}}$ and $\mathrm{GR}^{\mathrm{dim} / \mathrm{dim}}$ mice. Interestingly, activation of JNK1/2 was stronger in $\mathrm{GR}^{\mathrm{dim} / \mathrm{dim}}$ mice (Figure $3 \mathrm{~B}$ ), as was observed in $M k p 1^{-/}$ mice. These observations indicated that activation of JNK $1 / 2$ is stronger in $\mathrm{Mkp1}^{-/-}$and $\mathrm{GR} \operatorname{dim} / \mathrm{dim}$ mice.
JNK2, not JNK1, is an essential mediator of TNF-induced lethality. Because phospho-JNK1/2 levels were significantly higher in livers of $\mathrm{Mkp1}^{-/-}$and $\mathrm{GR}^{\mathrm{dim} / \mathrm{dim}}$ mice than in their WT controls, we studied the response of JNK-deficient mice to TNF. WT control, $J n k 1^{-/}$, and $J n k 2^{-/-}$mice were injected i.p. with $10 \mu \mathrm{g}$ TNF (an $\mathrm{LD}_{50}$ dose for C57BL/ 6 mice), and survival and body temperature were monitored. Although Jnk1 $1^{-/}$mice showed no change in sensitivity to TNF, Jnk2-/- mice were significantly more protected against TNF than control mice, as shown by the significantly lower mortality rate and less severe hypothermia (Figure 4, A and B). These findings indicated that JNK2, but not JNK1, is an essential mediator of TNF-induced lethal shock.

Furthermore, control and $J n k 2^{-/-}$mice were injected i.p. with $10 \mu \mathrm{g}$ TNF, and blood, liver, and ileum samples were harvested 0,1 , and 6 hours later. IL- 6 protein and Il6 mRNA levels, cytokine and chemokine levels in circulation, and proinflammatory gene expression levels in liver clearly demonstrated that $J n k 2^{-/-}$mice were protected against TNF-induced inflammation, especially at the later 6-hour time point (Figure 4, C and D, and Supplemental Figure 5). Together, these data indicated that JNK2 has a proinflammatory role.

Moreover, measuring proinflammatory gene expression levels in IECs and stainings of ileum samples with $\mathrm{H} \& \mathrm{E}$ and for active caspase 3 showed that inflammatory state, tissue damage, and acute cell death 1 hour after TNF injection was much more pronounced in the intestine of $J n k 2^{+/+}$than in $J n k 2^{-/-}$mice (Figure 4, E and F). As these characteristics were absent in $J n k 2^{-/-}$mice, we hypothesized that JNK2 might be the mediator of TNF-induced intestinal permeability. We therefore injected $J n k 2^{+/+}$and $J n k 2^{-{ }^{--}}$mice with $10 \mu \mathrm{g}$ TNF, followed 3 hours later by oral administration of 25 $\mathrm{mg} / \mathrm{ml}$ FITC-dextran. Blood samples were collected 8 hours after TNF challenge, and plasma was tested for FITC signal. Jnk2 $2^{+/+}$mice showed a stronger signal than Jnk2 $2^{-/}$mice (Figure 4G), which indicates that TNF induced more intestinal permeability in the Jnk2-/mouse. Taken together, these observations indicated that the effects of TNF on the epithelium (i.e., induction of inflammation and apoptosis) started very early, by 1 hour after TNF. Increased inflammation in liver and circulation seemed to be secondary to intestinal damage, as shown by the defect in intestinal permeability. Additionally, our findings provided evidence that JNK2 is a critical mediator of these TNF effects.

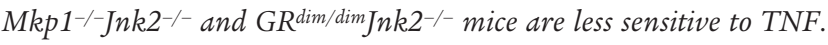
Since $M k p 1^{-1-}$ mice were very sensitive to the in vivo effects of TNF, and since MKP1 also dephosphorylated JNK1/2 in the TNF model, we wondered whether the sensitivity of $\mathrm{Mkp}^{1^{-/-}}$mice to TNF is due to overactive JNK kinases. To test this hypothesis, we generated

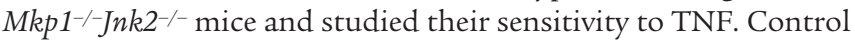

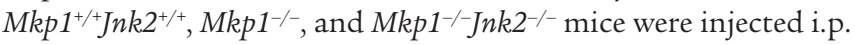
with $5 \mu \mathrm{g}$ TNF (which is lethal for $M k p 1^{-/-}$mice), and mortality and body temperature were monitored. The sensitivity of $\mathrm{Mkp}^{-1_{-}^{-}}$ Jnk2 $2^{-/-}$mice to TNF was intermediate between that of $M k p 1^{+/+}$ $J n k 2^{+/+}$and $\mathrm{Mkp1}^{-/-}$mice (Figure 5, A and B), which suggests that $J n k 2$ rescues TNF sensitivity, at least in part, in $M k p 1^{-1-}$ mice. The intermediate sensitivity of $M k p 1^{-/-} \mathrm{Jnk} 2^{-/-}$mice was confirmed by measuring IL-6 protein in circulation and Il6 mRNA in liver (Figure 5C). Furthermore, H\&E staining of ileum samples 1 hour after TNF injection showed that intestinal damage was comparable in $M k p 1^{+/+} J n k 2^{+/+}$and $M k p 1^{-/-J n k 2^{-/-}}$mice, but much more pronounced in $M k p 1^{-/}$mice (Figure 5D). These observations indicate

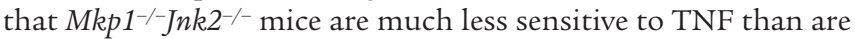
$M k p 1^{-/-}$mice, which indicates that the sensitivity of $M k p 1^{-/-}$mice 

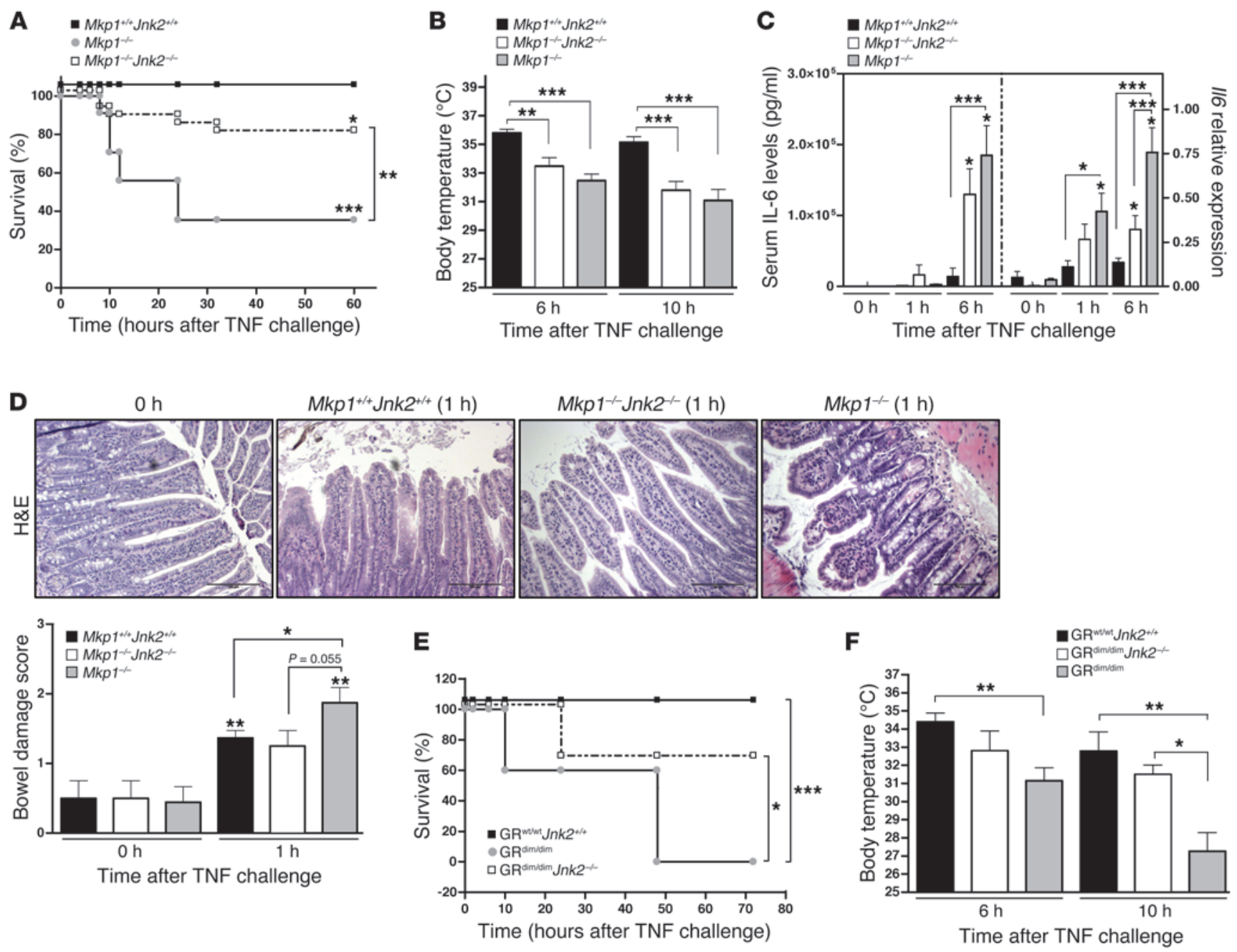

\section{Figure 5}

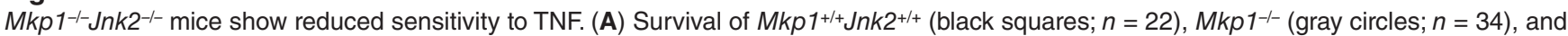

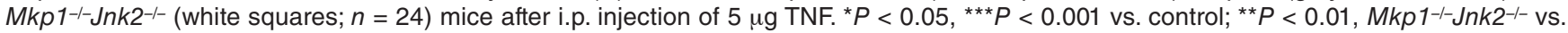
$\mathrm{Mkp1}^{-1-}$. (B) Body temperature of mice as in A. ${ }^{* *} P<0.01,{ }^{* *} P<0.001$. (C) Serum IL-6 concentrations and liver II6 mRNA levels 0,1 , and 6 hours after challenge with $5 \mu \mathrm{g}$ TNF ( $n=5$ per group). (D) Standard H\&E staining of ileum samples ( $n=5$ per group). The ileum was sampled 0 and 1 hour after i.p. injection of $5 \mu \mathrm{g}$ TNF. The micrograph at 0 hour is representative of all genotypes. Scale bars: $100 \mu \mathrm{m}$. Original magnification, $\times 40$. (C and D) ${ }^{\star} P<0.05$, ${ }^{* \star} P<0.01$, ${ }^{* \star *} P<0.001$ vs. 0 hours or as indicated by brackets. (B-D) Black bars, Mkp1+/Jnk2+/+; white bars,

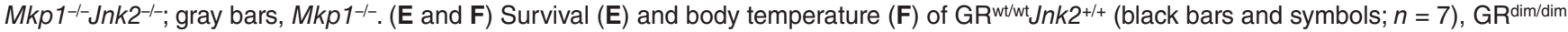

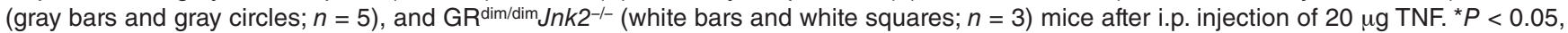
${ }^{\star \star} P<0.01,{ }^{\star \star \star} P<0.001$.

can be partly rescued by specifically inhibiting JNK2. We therefore conclude that JNK2 is one of the critical players responsible for the increased sensitivity of $\mathrm{Mkp1}^{-/-}$mice to TNF.

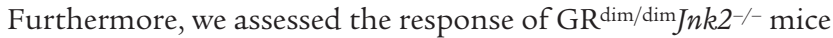
to shock. Control GR ${ }^{\mathrm{wt} / \mathrm{wt}} J n k 2^{+/+}, \mathrm{GR}^{\mathrm{dim} / \mathrm{dim}}$, and $\mathrm{GR}^{\mathrm{dim} / \mathrm{dim} J n k 2^{-/-}}$ mice were injected i.p. with $20 \mu \mathrm{g}$ TNF (which is lethal for GR $\operatorname{dim} / \mathrm{dim}$ mice with a mixed C57BL/6-FvB background), and mortality and body temperature were monitored. The sensitivity of GR dim/dim

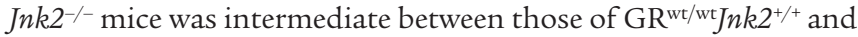
$\mathrm{GR}^{\mathrm{dim} / \mathrm{dim}}$ mice (Figure 5, E and F). These results suggest that JNK2, at least in part, rescues the sensitivity of $\mathrm{GR}^{\mathrm{dim} / \mathrm{dim}}$ mice to TNF, as

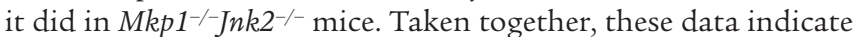
that dimerized GR protects against TNF-induced shock by induction of MKP1 and subsequent inhibition of JNK2.

\section{Discussion}

TNF is a pleiotropic cytokine with strong proinflammatory capacity, and it is a well validated drug target in several inflammatory disorders, such as rheumatoid arthritis, IBD, and psoriasis $(1,2)$. However, the use of biological drugs inhibiting TNF is very expensive and can result in unwanted side effects, such as tuberculosis (3).

It has been known for a long time that GCs protect against TNFinduced lethal shock and that this protection is mediated by binding of GCs to GR, a very potent antiinflammatory protein (7). However, therapy with GCs can also induce side effects, such as diabetes. It is believed that the side effects are induced by TA, whereas the antiinflammatory effects are mainly attributable to the TR actions of GR. Most studies claim that interaction of monomeric GR with transcription factors forms the basis for its antiinflammatory activ- 


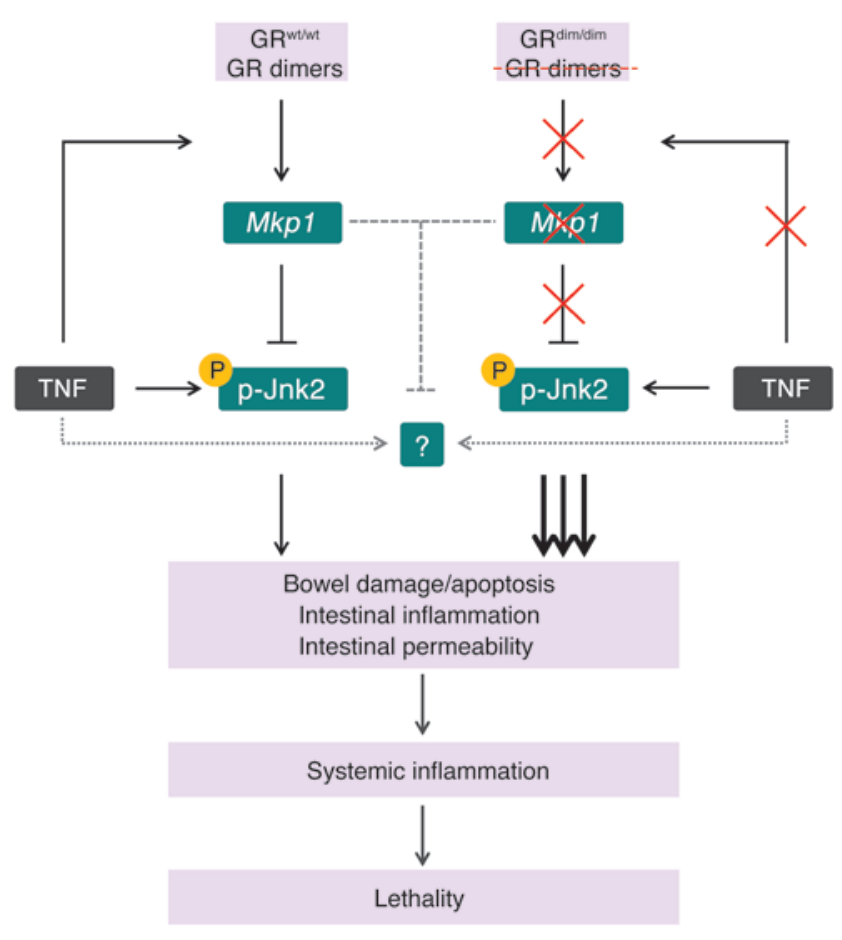

Figure 6

JNK2 is an essential player in TNF lethality, leading to cell death, bowel damage, intestinal inflammation, systemic inflammation, and consequent death. In GR ${ }^{\text {wt/wt }}$ mice, TNF can induce $M k p 1$ via GR dimers. Mkp1 dephosphorylates JNK2 and hence inhibits its activity. In GR dim/dim mice, TNF fails to induce $M k p 1$. These mice show prolonged and higher activation of JNK2, which results in a higher sensitivity to TNFinduced lethal shock. Dashed lines indicate the possible involvement of other MKP1 targets in the TNF pathway.

ity (32). Hence, the research community is currently investigating the development of GR ligands that favor TR. However, whether the TA potential of GR is also required for its antiinflammatory capacity remains unclear. Some studies have provided evidence that induction of antiinflammatory genes by GR dimers is indispensable for the antiinflammatory effects of GR (23). Indeed, several TA genes, such as $M k p 1$, have antiinflammatory activity. This has been demonstrated by many studies using $M k p 1^{-/-}$mice in several sepsis models, such as LPS administration, cecal ligation and puncture, and colon ascendens stent peritonitis, as well as in other disease models, such as collagen-induced arthritis (17-19).

To examine to which extent GR dimerization-dependent TA is required for protection against TNF, we tested the sensitivity of $\mathrm{GR}^{\mathrm{dim} / \mathrm{dim}}$ mice to TNF. These mice express a GR molecule that cannot form GR dimers and predominantly results in TR. We demonstrated that injection of TNF in GR ${ }^{\mathrm{dim} / \mathrm{dim}}$ mice caused a heightened sensitivity to its toxic effects compared with $\mathrm{GR}^{\mathrm{wt} / \mathrm{wt}}$ mice. We concluded that GR dimerization was indispensable for the protection provided by endogenous GCs against the acute inflammatory and lethal effects of TNF. The toxic effects of TNF were initiated early and resulted in severe hypothermia, high levels of circulating IL-6, intestinal damage, and subsequent high mortality. All these characteristics were substantially greater in $\mathrm{GR}^{\mathrm{dim} / \mathrm{dim}}$ than in $\mathrm{GR}^{\mathrm{wt}} / \mathrm{wt}$ mice. Furthermore, we demonstrated that GR $\mathrm{dim} / \mathrm{dim}$ mice did not induce expression of $M k p 1$ after treatment with DEX or TNF, which suggests that Mkp1 might play a role in the protection against TNF. Several studies have shown that MKP1 protein levels parallel mRNA levels. Valledor et al. showed that synthesis of MKP1 protein is tightly correlated with the time course of Mkp1 mRNA expression in LPS-treated macrophages (33). MKP1 protein levels were also found to follow the same pattern of induction as Mkp1 mRNA in $\mathrm{H}_{2} \mathrm{O}_{2}$-treated HeLa cells (34). We also measured MKP1 protein levels in our model, and our data showed that MKP1 protein levels indeed followed Mkp1 mRNA expression levels. Thus, the induction of Mkp1 mRNA expression and MKP1 protein levels both relied on GR dimerization.

The regulation of MKP1 is of much interest, but remains controversial. Recently, ChIP sequencing studies revealed a GRE site in the promoter region of $M k p 1(35,36)$. Furthermore, it was shown that DEX treatment leading to $M k p 1$ induction in liver and in various other cell types is dependent on GR dimerization (37). This was confirmed by our ChIP results, which indicated that binding of GR to $M k p 1$ and subsequent $M k p 1$ induction required GR dimerization. However, this was at odds with previous findings showing that in GR ${ }^{\mathrm{dim} / \mathrm{dim}}$ macrophages, $M k p 1$ can still be induced by DEX (17). Tissue specificity could be the reason for this discrepancy.

The prominent role of $M k p 1$ in the control of the excessive inflammation induced by TNF was confirmed in $M k p 1^{-/-}$mice, which were extremely sensitive to TNF compared with $M k p 1^{+/+}$ mice. These findings correlated with the antiinflammatory effects of MKP1 described in other inflammation models (17-19).

TNF has previously been shown to mediate disruption of the intestinal mucosal barrier, which is followed by translocation of invasive bacteria into the blood stream after endotoxemia $(38,39)$. The present study showed that TNF resulted in intestinal damage and inflammation and disruption of the intestinal barrier as early as 1 hour after TNF challenge, and systemic inflammation followed later, at the 6-hour time point. This inflammation was characterized by high levels of circulating chemokines and cytokines and high expression levels of proinflammatory genes in the liver. Moreover, this cascade of inflammation and apoptosis in the gut followed by systemic inflammation was tightly regulated by MKP1, as $\mathrm{Mkp1}^{-/-}$mice were hypersensitive to TNF-mediated apoptosis, inflammation, and subsequent lethality.

It was crucial to show that GCs did not protect against TNFinduced shock in $M k p 1^{-/-}$mice. A functional $M k p 1$ gene is probably required for maximal protective effects, as previously shown for DEX protection against endotoxic shock (40). In that study, DEX only partially protected $M k p 1^{-/-}$mice from endotoxic shock, whereas WT mice were completely protected from endotoxin-induced mortality. Our present results indicated that DEX pretreatment, in the absence of MKP1, did not fully protect $M k p 1^{-1-}$ mice from the lethal effect of TNF. Thus, MKP1 was required for the protection provided by GCs against TNF. However, TNF-induced mortality was somehow delayed in DEX-versus solvent-treated $M k p 1^{-/-}$mice. Despite the essential role of MKP1 in the protective effects of GCs in several inflammatory models, including our TNF model, some GC effects occur independently of MKP1. GCs might have some direct antiinflammatory effects, or they might also act via the induction of other antiinflammatory proteins. This idea is supported by the prior finding that inhibition of protein synthesis in bone marrow-derived mast cells from $M k p 1^{-/-}$mice partly reverses the antiinflammatory effects of GCs (41).

In keeping with the well-known dephosphorylation actions of MKP1, we showed here that $M k p 1^{-/-}$mice exhibited prolonged 
JNK1/2 phosphorylation. Moreover, GR ${ }^{\mathrm{dim} / \mathrm{dim}}$ mice had higher levels of phospho-JNK1/2. To determine whether increased JNK activation indeed forms the basis of the hypersensitivity of $\mathrm{Mkp1}^{-/-}$and $\mathrm{GR}^{\mathrm{dim} / \mathrm{dim}}$ mice to TNF, we studied the effects of TNF in $J n k 1^{-/-}$and $J n k 2^{-/-}$mice. We found that $J n k 2^{-/-}$mice, but not $J n k 1^{-/-}$mice, were resistant to TNF. The absence of JNK2 led to resistance against very early TNF-induced gut epithelial cell death, intestinal inflammation, and intestinal permeability as well as against subsequent systemic inflammation. We previously demonstrated that bowel damage is a very fast and essential step in TNF-induced lethal inflammation $(42,43)$, and other groups have shown that TNF mediates gut epithelial cell death in genetic mouse models of IBD, such as in the IKK $\gamma$ knockout mouse (44). JNK molecules have been shown to mediate the apoptosis activity of TNF $(45,46)$, and JNK2 has been shown to induce apoptosis by regulating both mitochondrial and lysosomal death pathways $(24,25)$. Furthermore, several studies have indicated a role for JNK in regulating apoptosis in IECs $(47,48)$. Additionally, Ray et al. showed increased levels of both phospho-JNK1 and phospho-JNK2 in IEC-6 cells upon TNF challenge when the cells were also treated with MKP1 siRNA (48). That JNK increase subsequently resulted in more apoptosis in these cells, mediated by activated caspase 9 and caspase 3 . Phospho-JNK1/2 levels were induced in IEC- 6 cells within 15 minutes of TNF treatment and declined after 1 hour. This is in accordance with our present results using liver samples.

Here, we provided evidence that JNK2, but not JNK1, was an essential player in mediating apoptosis of IECs in response to TNF. We therefore conclude that JNK2 is a critical mediator of TNF lethality. Our data support the idea that JNK2 plays an essential role in the in vivo effects of TNF by mediating early cell death of IECs, which leads to disruption of the intestinal barrier and consequent systemic inflammation.

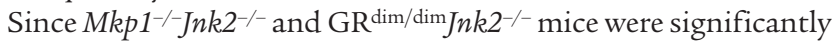
less sensitive to TNF than were $M k p 1^{-/-}$and $\mathrm{GR}^{\mathrm{dim} / \mathrm{dim}}$ mice, respectively, the hypersensitivity of $M k p 1^{-/-}$and $\mathrm{GR}$ dim/dim mice was largely due to JNK2. Since $M k p 1^{-/-} J n k 2^{-/-}$mice did show the same extent of intestinal damage as control mice, JNK2 seemed to be critical for induction of intestinal damage. This is confirmed by another study showing that JNK mediates apoptosis of IECs (48). Furthermore, the authors show that knockdown of MKP1 in IECs by using siRNA enhances the activity of JNK and increases subsequent apoptosis. However, in our study, the response to TNF in $M k p 1^{-/-}$

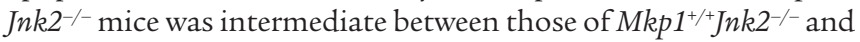
$M k p 1^{-/-}$mice. Thus, it is likely that the TNF pathway involves other players contributing to its lethal effects, especially its inflammatory effects, such as MAPK p38 and ERK. p38 in particular seems to be an excellent candidate, because the substrate specificity of MKP1 is greater for p38 and JNK than for $\operatorname{ERK}(18,19)$. Moreover, several studies have proven an important role for p38 in mediating acute inflammation, such as the successful use of a MAPK inhibitor in vivo by Bhattacharyya et al. (49). These authors showed that a specific $\mathrm{p} 38$ inhibitor protected macrophage-specific $G R^{-/-}$mice from LPS lethality attributed to impaired induction of MKP1. Furthermore, a critical role for $\mathrm{p} 38$ and subsequent NF- $\mathrm{KB}$ activation was recently described in several reports. It was shown that curcumin, which has antiinflammatory and antioxidant activities, protects the intestinal mucosal barrier by induction of MKP1 and subsequent inactivation of $\mathrm{p} 38$ and of NF- $\mathrm{\kappa B}$-mediated transcription (50). In addition, some reports suggest that ERK could be an important mediator of TNF-induced shock and provide a link with MKP1 $(51,52)$. However, because we observed identical phospho-p38 and phospho-ERK levels in $\mathrm{Mkp1}^{\mathrm{I}^{++}}$and $\mathrm{Mkp1}^{-/-}$mice, the contribution of these MAPKs in the context of the present study can be ruled out. It is probable that other yet-unidentified targets of MKP1 could account for the TNF-induced toxic effects. Taken together, our results suggest that by limiting the duration of JNK2 activity, MKP1 provides a crucial negative feedback mechanism of GCs during inflammatory responses.

In summary, we showed that dimerization of GR was essential for protection against acute TNF-mediated inflammation and critical for Mkp1 induction, and hence controlled activation of the proapoptotic JNK2. Our observations suggest that JNK2 mediates TNF lethality by inducing intestinal apoptosis and inflammation as well as subsequent systemic inflammation (Figure 6). To our knowledge, this is the first in vivo evidence that GR dimerization is important in the regulation of TNF-induced apoptosis.

Another important conclusion of our work is that both antiapoptotic and antiinflammatory effects of GCs necessitate the induction of gene expression and require GR dimerization. Thus, the dissociation model calling for prevention of GR-induced gene induction and stimulation of GR transrepression by synthetic GR ligands (i.e., selective GR agonists [SEGRAs]), although attractive, has some limitations, at least in this type of acute inflammation. Especially in acute inflammatory settings, GR-induced gene expression makes a major contribution to protection, and hence inhibition of GR dimerization might be dangerous.

\section{Methods}

Mice. C57BL6/J mice were purchased from Janvier. GR dim mice were generated by Reichardt et al. (21) and backcrossed on a FVB/N background. Heterozygous $\mathrm{GR}^{\mathrm{dim}}$ mice were intercrossed to generate $\mathrm{GR}^{\mathrm{dim} / \mathrm{dim}}$ homozygous mutant mice and $\mathrm{GR}^{\mathrm{wt} / \mathrm{wt}}$ homozygous WT mice. Mkp1 $1^{-/-}$mice had a C57BL6/J background and were generated by Bravo et al. (53) and provided by Y. Liu (Ohio State University, Columbus, Ohio, USA). Jnk1-/and Jnk2 $2^{-/}$mice had a C57BL6/J background and were purchased from The Jackson Laboratories. Pure C57BL6/J mice were used as controls for $M k p 1^{-/-}, J n k 1^{-/-}$, and $J n k 2^{-/-}$mice. In order to generate $\mathrm{Mkp1}^{-{ }^{--} J n k 2^{-/-} \text {and }}$

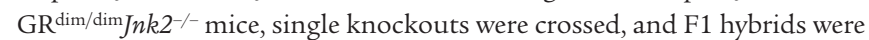

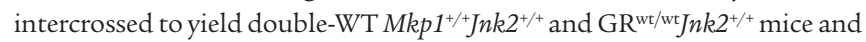

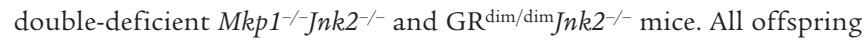
were genotyped by PCR on genomic DNA isolated from tail biopsies. The mice were kept in individually ventilated cages under a 12-hour dark/ 12-hour light cycle in a conventional animal house and received food and water ad libitum. All mice were used at 8-12 weeks of age.

Reagents. Recombinant mouse TNF was produced in E. coli and purified to homogeneity in our laboratories. TNF had a specific activity of $1.2 \times 10^{8}$ $\mathrm{IU} / \mathrm{mg}$ and no detectable endotoxin contamination.

Injections and sampling. TNF was diluted in pyrogen-free PBS. All injections were given i.p. Blood was withdrawn with a glass capillary from the retroorbital plexus and allowed to clot overnight at $4^{\circ} \mathrm{C}$. The clot was then removed, and serum was collected after centrifugation at $20,000 \mathrm{~g}$ for 10 minutes and stored at $-20^{\circ} \mathrm{C}$. For sampling liver tissue, mice were killed by cervical dislocation, and tissue samples were fixed briefly in $4 \%$ paraformaldehyde and embedded in paraffin by a standard protocol (Tissue-Tek VIP; Sakura). A piece of liver was stored in RNA later (Qiagen) for RNA preparation, and the rest was snap-frozen in liquid nitrogen and stored at $-80^{\circ} \mathrm{C}$.

Measurements of cytokines in circulation. Serum IL- 6 was determined with a 7TD1 bioassay (54). Serum samples were also assayed for several cytokines using Luminex technology (Bio-Rad, Nazareth-Eke) following the manufacturer's protocol. 
Tissue section, histology, and immunohistochemistry. Tissue sections of $4 \mu \mathrm{m}$ were cut and stained with $\mathrm{H} \& \mathrm{E}$ using standard techniques. After staining, the labels on the bowel sections were blinded, and tissue damage was quantified by 4 neutral observers using the necrotizing enterocolitis scoring system published and validated by Halpern et al. (30). The mean value of their estimations was used. For caspase 3 staining, $4-\mu \mathrm{m}$ sections were deparaffinized for antigen retrieval (target retrieval solution; Dako) and then rehydrated. For visualization, we used an antibody against active caspase 3 (APO active 3 antibody specific active caspase 3 detection Kit [PE]; Cell Technology), EnVision+ HRP (Dako), and DAB (Dako). The slides were counterstained with hematoxylin solution (Mayer) and dehydrated. Caspase 3-positive cells were counted in 5 random $\times 40$ fields in a double-blinded fashion. Negative controls were made by substituting buffer for primary antibody.

qPCR analysis. Tissue samples were collected in RNA later (Qiagen), and RNA was isolated with the RNeasy Mini kit (Qiagen) according to the manufacturer's instructions. RNA concentration was measured with Nanodrop 1000 (Thermo Scientific), and $1 \mu \mathrm{g}$ RNA was used to prepare cDNA with Superscript II (Invitrogen). qPCR was performed using the Roche LightCycler 480 system (Applied Biosystems). The best-performing housekeeping genes were determined by Genorm (55). Results are given as relative expression values normalized to the geometric mean of the housekeeping genes.

MKP1 ELISA. Protein was extracted from liver samples by homogenizing tissue in $0.5 \%$ CHAPS lysis buffer containing protease inhibitors. The supernatant was stored at $-70^{\circ} \mathrm{C}$. Intestinal MKP1 was measured using a commercially available ELISA assay (USCNK Life Sciences Inc.).

Western blot analysis. Whole tissue lysates containing $100 \mu \mathrm{g}$ protein were separated by electrophoresis in a $10 \%$ gradient SDS-polyacrylamide gel and transferred to nitrocellulose filters. The membranes were incubated overnight at $4^{\circ} \mathrm{C}$ with primary antibodies against phospho-JNK1/2 (1:1,000; catalog no. 9910s, Cell Signaling) and total JNK (1:1,000; catalog no. 554285, BD Biosciences - Pharmingen), phospho-p38 (1:1,000; catalog no. 9910s, Cell Signaling), phospho-ERK1/2 (1:1,000; catalog no. 9910s, Cell Signaling), and actin (1:10,000; MP Biomedicals) as an internal control. Blots were washed with Tris-buffered saline containing $0.1 \%$ Tween 20, then incubated for 1 hour at room temperature with anti-rabbit antibody (1:10,000; catalog no. 926-32211, Li-cor) and anti-mouse antibody (1:15,000; catalog no. 926-32220, Li-cor). Immunoreactive bands were detected using the Odyssey Infrared Imager (Li-cor) and quantified using Odyssey Application software (version 2.1, Li-cor).

ChIP. Liver samples were homogenized in cold PBS and crosslinked in $2 \%$ paraformaldehyde for 10 minutes at room temperature. The reaction was stopped with $1 \mathrm{M}$ glycine. Liver lysates were sonicated and then subjected to IP with rabbit anti-GR antibody ( $5 \mu \mathrm{g}$ per IP; catalog no. sc8992, Santa Cruz Biotechnology). The material was decrosslinked by raising the incubation temperature to $65^{\circ} \mathrm{C}$ for 16 hours. The recovered DNA was purified by the PCR purification kit (Qiagen). qPCR was performed using the Roche LightCycler 480 system (Applied Biosystems). Mkp1 primer pairs were as follows (based on ref. 56): MKP1-1 (1.3), 5'-CAAGAGCTAAGAGAGGCCAAA-3' and 5'-CACGGAGTTGGATACACAAACA-3'; MKP1-2 (2.4), 5'-GTGCCTGGCTCTGCATCGAAAATGGAA-3' and 5'-TGGCTCAGACACTGCTGTCCCCTCT-3'; MKP1-3 (2.8), $5^{\prime}$-GCTTCCCAGATGTGCCAAG- $3^{\prime}$ and $5^{\prime}$-CCAAACCTTGAGCCAGAGCAGTG-3'; MKP1-4 (2.9), 5'-CTTAGGGTGAACTGACATC-3' and 5'-CTTTGAGCTCACTTCCTGTTTTGTG-3'.

Intestinal permeability. Animals underwent an in vivo intestinal permeability assay at 8 hours after TNF treatment using methods described previously (57). At 3 hours after TNF, $200 \mu$ FITC-dextran $(25 \mathrm{mg}$ 4.4-kDa FITC-dextran in $1 \mathrm{ml}$ PBS) was administered orally. At 8 hours after TNF, blood was collected into heparinized Eppendorf tubes and centrifuged at $10,000 \mathrm{~g}$ for 10 minutes. Plasma was collected and subsequently assayed for concentration of FITC-dextran.

Statistics. Survival curves (Kaplan-Meyer plots) were compared by logrank test, and final outcomes by $\chi^{2}$ test. Statistical significance of differences between groups was evaluated by 2 -tailed Student's $t$ tests with $95 \%$ confidence intervals and by 2 -way ANOVA. All data are expressed as mean \pm SEM. $P$ values less than 0.05 were considered significant.

Study approval. All animal experiments were approved by the institutional ethics committee for animal welfare of the Faculty of Sciences, Ghent University.

\section{Acknowledgments}

We thank Joke Vanden Berghe, Wilma Burm, and Amelie Depuis for technical assistance and Amin Bredan for editing the manuscript. We are grateful to Linda Van Geert, Debby Roels, and Carine Van Laere for animal care. The work was supported by the Fund for Scientific Research, Flanders; the Belgian Interuniversity Attraction Poles program (IAP VI/18); the agency for Innovation by Science and Technology (IWT); the Belgian Association Against Cancer; and the Deutsche Forschungsgemeinschaft (Tu 220/3).

Received for publication July 15, 2011, and accepted in revised form April 4, 2012.

Address correspondence to: Claude Libert, VIB - Ghent University, FSVM Building, Technologiepark 927, B-9052 Zwijnaarde, Ghent, Belgium. Phone: 3293313700; Fax: 3293313609; E-mail: Claude.Libert@ugent.be.
1. Berry MA, et al. Evidence of a role of tumor necrosis factor alpha in refractory asthma. N Engl J Med. 2006;354(7):697-708.

2. Kollias G, Douni E, Kassiotis G, Kontoyiannis D. The function of tumour necrosis factor and receptors in models of multi-organ inflammation, rheumatoid arthritis, multiple sclerosis and inflammatory bowel disease. Ann Rheum Dis. 1999;58(suppl 1):I32-I39.

3. Wallis RS. Tumour necrosis factor antagonists: structure, function, and tuberculosis risks. Lancet Infect Dis. 2008;8(10):601-611.

4. Karin M, Lin A. NF-kappaB at the crossroads of life and death. Nat Immunol. 2002;3(3):221-227.

5. Tracey KJ, et al. Shock and tissue injury induced by recombinant human cachectin. Science. 1986; 234(4775):470-474.

6. Bertini R, Bianchi M, Ghezzi P. Adrenalectomy sensitizes mice to the lethal effects of interleukin 1 and tumor necrosis factor. J Exp Med. 1988; 167(5):1708-1712.
7. Libert C, Van Bladel S, Brouckaert P, Fiers W. The influence of modulating substances on tumor necrosis factor and interleukin- 6 levels after injection of murine tumor necrosis factor or lipopolysaccharide in mice. J Immunother (1991). 1991;10(4):227-235.

8. Brouckaert P, Everaerdt B, Fiers W. The glucocorticoid antagonist RU38486 mimics interleukin-1 in its sensitization to the lethal and interleukin-6inducing properties of tumor necrosis factor. Eur J Immunol. 1992;22(4):981-986.

9. Van Bogaert T, et al. TNF inhibits glucocorticoid receptor function in mice: A strong signal towards lethal shock. J Biol Chem. 2011;286(30):26555-26567.

10 . Jonat $\mathrm{C}$, et al. Antitumor promotion and antiinflammation: down-modulation of AP-1 (Fos/Jun) activity by glucocorticoid hormone. Cell. 1990; 62(6):1189-1204

11. Scheinman RI, Gualberto A, Jewell CM, Cidlowski JA, Baldwin AS Jr. Characterization of mechanisms involved in transrepression of NF-kappa B by activated glucocorticoid receptors. Mol Cell Biol. 1995;15(2):943-953.

12. De Bosscher K. Selective Glucocorticoid Receptor modulators. J Steroid Biochem Mol Biol. 2010; 120(2-3):96-104.

13. Robertson $\mathrm{S}$, et al. Abrogation of glucocorticoid receptor dimerization correlates with dissociated glucocorticoid behavior of compound a. J Biol Chem. 2010;285(11):8061-8075.

14. Kassel O, Sancono A, Kratzschmar J, Kreft B, Stassen M, Cato AC. Glucocorticoids inhibit MAP kinase via increased expression and decreased degradation of MKP-1. EMBO J. 2001;20(24):7108-7116.

15. Clark AR. Anti-inflammatory functions of glucocorticoid-induced genes. Mol Cell Endocrinol. 2007;275(1-2):79-97.

16. Clark AR, Lasa M. Crosstalk between glucocorticoids and mitogen-activated protein kinase signalling pathways. Curr Opin Pharmacol. 2003;3(4):404-411.

17. Abraham SM, et al. Antiinflammatory effects of 
dexamethasone are partly dependent on induction of dual specificity phosphatase 1. J Exp Med. 2006; 203(8):1883-1889.

18. Hammer $M$, et al. Increased inflammation and lethality of Dusp1-/- mice in polymicrobial peritonitis models. Immunology. 2010;131(3):395-404.

19. Salojin KV, Owusu IB, Millerchip KA, Potter M, Platt $\mathrm{KA}$, Oravecz T. Essential role of MAPK phosphatase1 in the negative control of innate immune responses. J Immunol. 2006;176(3):1899-907.

20. Heck S, et al. A distinct modulating domain in glucocorticoid receptor monomers in the repression of activity of the transcription factor AP-1.EMBOJ. 1994;13(17):4087-4095.

21. Reichardt HM, et al. DNA binding of the glucocorticoid receptor is not essential for survival. Cell. 1998;93(4):531-541.

22. Kleiman A, et al. Glucocorticoid receptor dimerization is required for survival in septic shock via suppression of interleukin-1 in macrophages. FASEBJ. 2011;26(2):722-729.

23. Tuckermann JP, et al. Macrophages and neutrophils are the targets for immune suppression by glucocorticoids in contact allergy. J Clin Invest. 2007;117(5):1381-1390.

24. Dietrich N, et al. JNK2 mediates TNF-induced cell death in mouse embryonic fibroblasts via regulation of both caspase and cathepsin protease pathways. Cell Death Differ. 2004;11(3):301-313.

25. Liedtke C, Trautwein C. The role of JNK2 in toxic liver injury. J Hepatol. 2006;45(5):762-764.

26. Fiers W, et al. TNF: its potential as an antitumour agent. Dev Biol Stand. 1988;69:143-151.

27. Brouckaert P, Libert C, Everaerdt B, Fiers W. Selective species specificity of tumor necrosis factor for toxicity in the mouse. Lymphokine Cytokine Res. 1992;11(4):193-196.

28. Yang D, Xie P, Guo S, Li H. Induction of MAPK phosphatase- 1 by hypothermia inhibits TNFalpha-induced endothelial barrier dysfunction and apoptosis. Cardiovasc Res. 2010;85(3):520-529.

29. Piguet PF, Vesin C, Guo J, Donati Y, Barazzone C. TNF-induced enterocyte apoptosis in mice is mediated by the TNF receptor 1 and does not require p53. Eur J Immunol. 1998;28(11):3499-3505.

30. Halpern MD, et al. Hepatic inflammatory mediators contribute to intestinal damage in necrotizing enterocolitis. Am J Physiol Gastrointest Liver Physiol. 2003;284(4):G695-G702

31. Karin M, Gallagher E. TNFR signaling: ubiquitin-conjugated TRAFfic signals control stop-andgo for MAPK signaling complexes. Immunol Rev. 2009;228(1):225-240.
32. Reichardt HM, et al. Repression of inflammatory responses in the absence of DNA binding by the glucocorticoid receptor. EMBOJ. 2001;20(24):7168-7173.

33. Valledor AF, Xaus J, Comalada M, Soler C, Celada A. Protein kinase $\mathrm{C}$ epsilon is required for the induction of mitogen-activated protein kinase phosphatase- 1 in lipopolysaccharide-stimulated macrophages. J Immunol. 2000;164(1):29-37.

34. Kuwano Y, et al. MKP-1 mRNA stabilization and translational control by RNA-binding proteins $\mathrm{HuR}$ and NF90. Mol Cell Biol. 2008;28(14):4562-4575.

35. Reddy TE, et al. Genomic determination of the glucocorticoid response reveals unexpected mechanisms of gene regulation. Genome Res. 2009; 19(12):2163-2171.

36. Shipp LE, et al. Transcriptional regulation of human dual specificity protein phosphatase 1 (DUSP1) gene by glucocorticoids. PloS One. 2010;5(10):e13754.

37. Frijters R, et al. Prednisolone-induced differential gene expression in mouse liver carrying wild type or a dimerization-defective glucocorticoid receptor. BMC Genomics. 2010;11:359.

38. Goldman G, Soffer D, Heller L, Aderka D, Lahat A, Klausner JM. Tumour necrosis factor mediates bacterial translocation after haemorrhagic shock and endotoxaemia. Eur J Surg. 2001;167(4):299-304.

39. McGuckin MA, Eri R, Simms LA, Florin TH, Radford-Smith $\mathrm{G}$. Intestinal barrier dysfunction in inflammatory bowel diseases. Inflamm Bowel Dis. 2009;15(1):100-113.

40. Wang X, Nelin LD, Kuhlman JR, Meng X, Welty SE, Liu Y. The role of MAP kinase phosphatase- 1 in the protective mechanism of dexamethasone against endotoxemia. Life Sci. 2008;83(19-20):671-680.

41. Maier JV, et al. Dual specificity phosphatase 1 knockout mice show enhanced susceptibility to anaphylaxis but are sensitive to glucocorticoids. Mol Endocrinol. 2007;21(11):2663-2671.

42. Takahashi N, et al. IL-17 produced by Paneth cells drives TNF-induced shock. J Exp Med. 2008; 205(8):1755-1761.

43. Van Molle W, et al. HSP70 protects against TNFinduced lethal inflammatory shock. Immunity. 2002;16(5):685-695.

44. Nenci A, et al. Epithelial NEMO links innate immunity to chronic intestinal inflammation. Nature. 2007;446(7135):557-561

45. Kamata H, Honda S, Maeda S, Chang L, Hirata H, Karin M. Reactive oxygen species promote TNFalpha-induced death and sustained JNK activation by inhibiting MAP kinase phosphatases. Cell. 2005; 120(5):649-661.

46. Ventura JJ, Hubner A, Zhang C, Flavell RA, Shokat
KM, Davis RJ. Chemical genetic analysis of the time course of signal transduction by JNK. Mol Cell. 2006;21(5):701-710

47. Jin S, Ray RM, Johnson LR. Rac1 mediates intestinal epithelial cell apoptosis via JNK. Am J Physiol Gastrointest Liver Physiol. 2006;291(6):G1137-G1147.

48. Ray RM, Jin S, Bavaria MN, Johnson LR. Regulation of JNK activity in the apoptotic response of intestinal epithelial cells. Am J Physiol Gastrointest Liver Physiol. 2011;300(5):G761-G770.

49. Bhattacharyya S, Brown DE, Brewer JA, Vogt SK, Muglia LJ. Macrophage glucocorticoid receptors regulate Toll-like receptor 4-mediated inflammatory responses by selective inhibition of p38 MAP kinase. Blood. 2007;109(10):4313-4319.

50. Song WB, et al. Curcumin protects intestinal mucosal barrier function of rat enteritis via activation of MKP-1 and attenuation of p38 and NF-kappaB activation. PloS One. 2010;5(9):e12969.

51. Bladh LG, Johansson-Haque K, Rafter I, Nilsson S, Okret S. Inhibition of extracellular signal-regulated kinase (ERK) signaling participates in repression of nuclear factor (NF)-kappaB activity by glucocorticoids. Biochim Biophys Acta. 2009;1793(3):439-446.

52. Onda K, Nagashima M, Kawakubo Y, Inoue S, Hirano T, Oka K. Mitogen-activated protein kinase kinase 1/ extracellular signal-regulated kinase (MEK-1/ ERK) inhibitors sensitize reduced glucocorticoid response mediated by TNFalpha in human epidermal keratinocytes (HaCaT). Biochem Biophys Res Commun. 2006;351(1):266-272.

53. Dorfman K, Carrasco D, Gruda M, Ryan C, Lira SA, Bravo R. Disruption of the erp/mkp-1 gene does not affect mouse development: normal MAP kinase activity in ERP/MKP-1-deficient fibroblasts. Oncogene. 1996;13(5):925-931.

54. Van Snick J, et al. Purification and NH2-terminal amino acid sequence of a T-cell-derived lymphokine with growth factor activity for B-cell hybridomas. Proc Natl Acad Sci U S A. 1986;83(24):9679-9683.

55. Vandesompele J, et al. Accurate normalization of real-time quantitative RT-PCR data by geometric averaging of multiple internal control genes. Genome Biol. 2002;3(7):RESEARCH0034.

56. Tchen CR, Martins JR, Paktiawal N, Perelli R, Saklatvala J, Clark AR. Glucocorticoid regulation of mouse and human dual specificity phosphatase 1 (DUSP1) genes: unusual cis-acting elements and unexpected evolutionary divergence. J Biol Chem. 2009;285(4):2642-2652.

57 . Bansal V, et al. Traumatic brain injury and intestinal dysfunction: uncovering the neuro-enteric axis. J Neurotrauma. 2009;26(8):1353-1359. 